\title{
37. 保健体育の評価に関する一考察
}

新居话工業活等専門学校 片上進, 柴学男

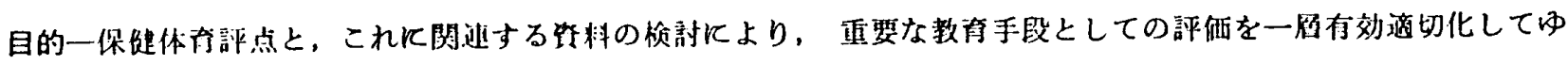
きたい.

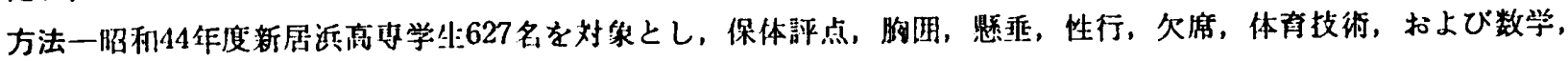

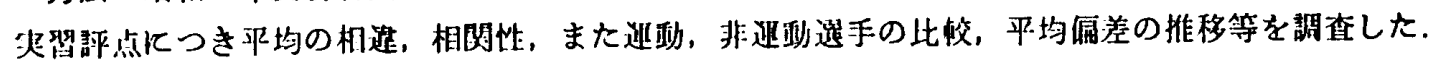

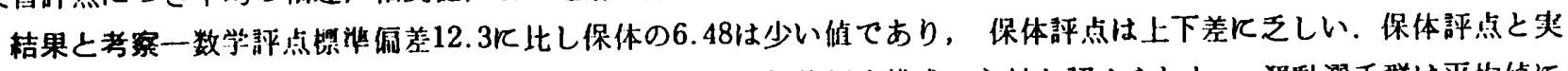

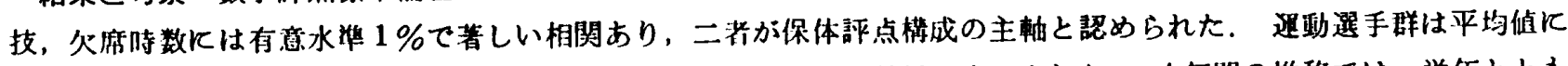

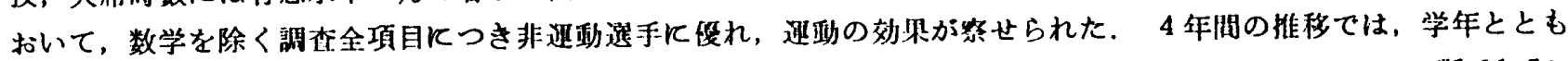

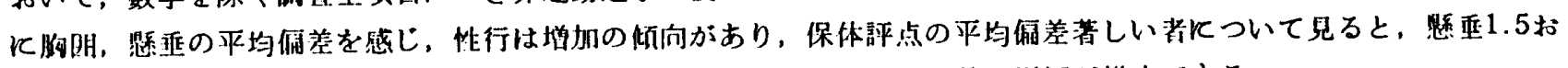

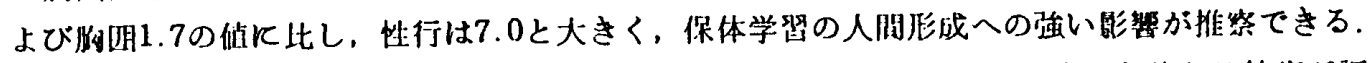

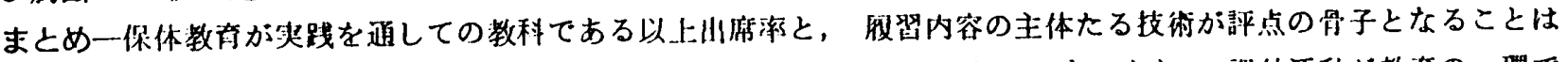

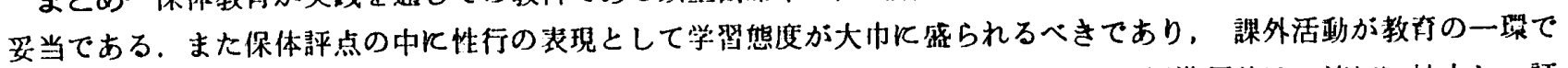

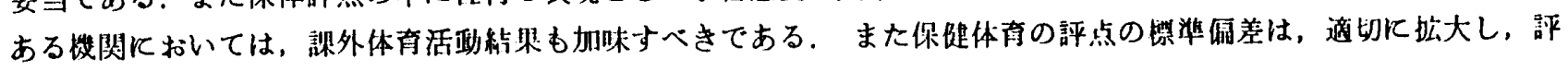
点效果が充分あらわれるよう留意すべきである.

\section{8. $50 \mathrm{~m}$ 疾走よりみた体力評価}

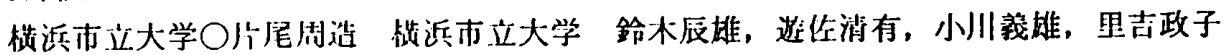

休力测定の各项目の中で，50m疾退はこれを正しく評佂すれば，個人の体力の全貌をろかが资料となりうるとも

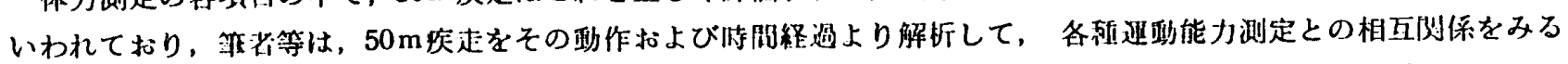

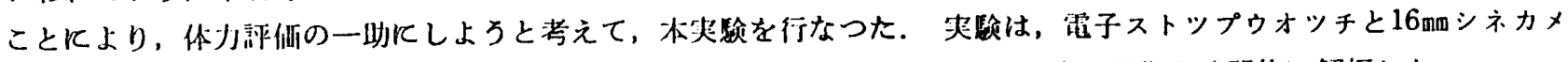

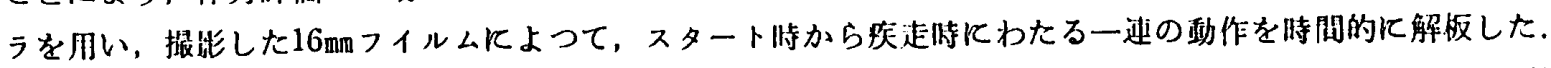

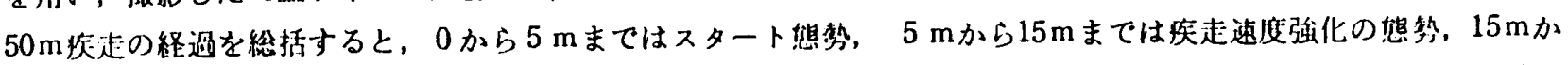

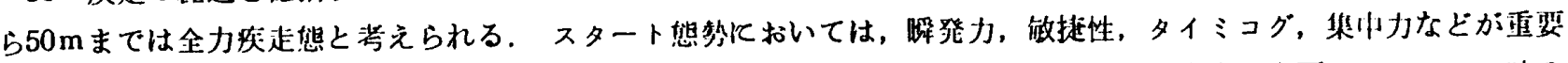

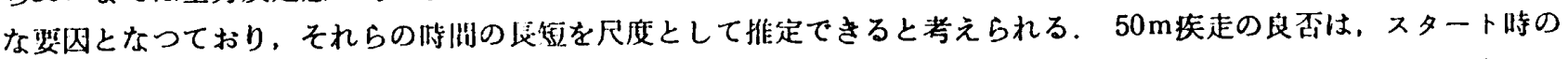

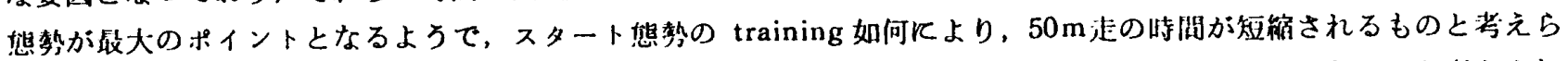
れる。またこれК伴なう skill, coordination, agility，などの発達を期待することもできるのではないかと考えられ

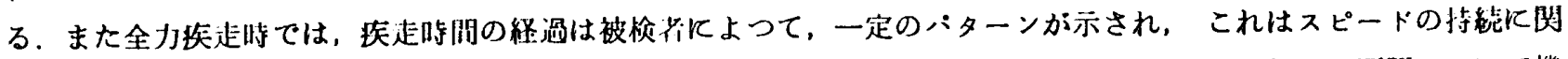

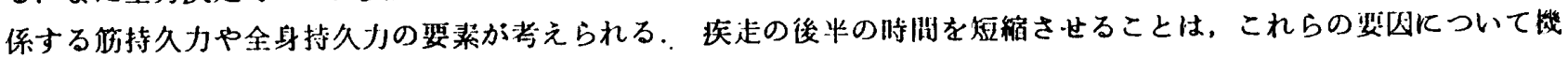
能の向上をはからねばならない。

\section{9. 体力評価方法の検討}

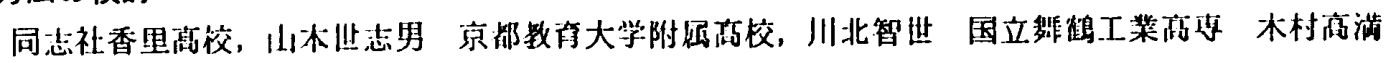

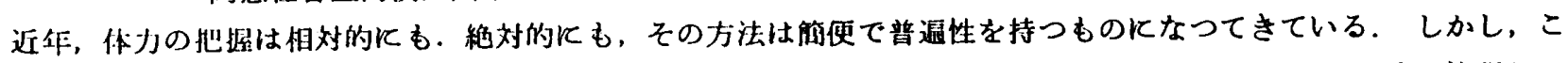

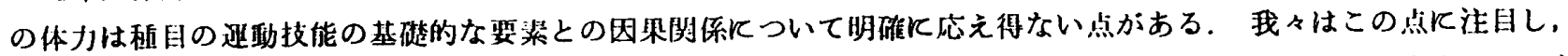

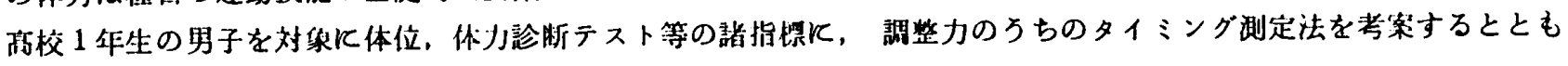
にこれを玑え，体力の稳合的な制定法を検討した。

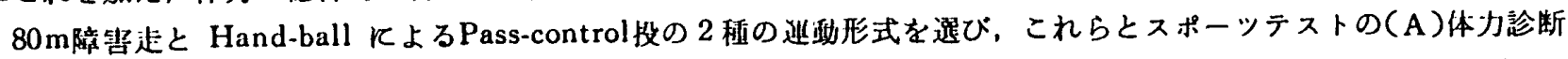

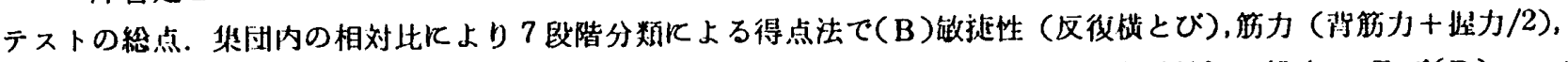

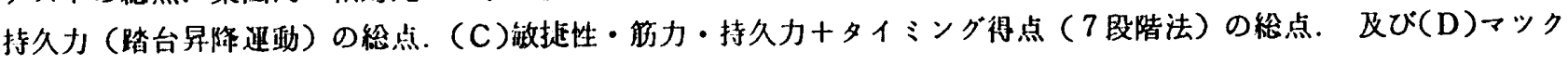
ロイ作力級别指数の 4 法とを比挩した。 この絬果，
(A) $\left\{\begin{array}{l}0.566 \\ 0.156\end{array}\right.$
(B) $\left\{\begin{array}{l}0.414 \\ 0.057\end{array}\right.$
(C) $\left\{\begin{array}{l}0.622 \\ 0.244\end{array}\right.$
(D) $\left\{\begin{array}{l}0.162 \\ 0.204\end{array}\right.$

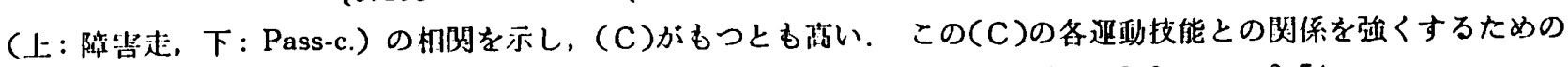
算式は，(上：㜔) $6.3 \mathrm{~S}+5.8 \mathrm{~F}+4.1 \mathrm{E}+3.0 \mathrm{C}, \mathrm{r}=0.75,3.5 \mathrm{~S}+8.6 \mathrm{~F}+3.0 \mathrm{E}+9.0 \mathrm{C}, \mathrm{r}=0.54$.

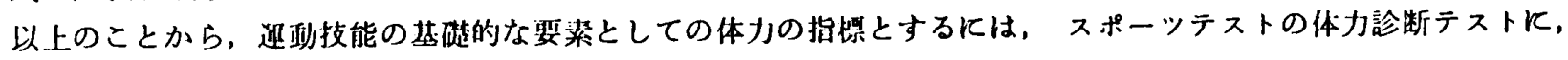
タイミングやバランスなどの神経支配能力検㿽を加味する必要性の高いことを提起する. 